\title{
DEVELOPMENT AND EVALUATION OF A CONTINUOUS MICROWAVE PROCESSING SYSTEM FOR HYDROCARBON REMOVAL FROM SOLIDS
}

\author{
A.J. Buttress. E, Binner, C. Yi, P. Palade, J.P. Robinson'ㄹ, S.W. Kingman. \\ Industrial Microwave Processing Research Group, Faculty of Engineering, University of Nottingham, NG7 2RD, \\ UK. \\ a - corresponding author john.robinson@nottnigham.ac.uk
}

\section{ABSTRACT}

A continuous conveyor-belt processing concept using microwave heating was developed and evaluated. Four hydrocarbon-contaminated soils were used as model feedstocks, and the degree of organic removal was assessed against the power and energy input to the process. The findings of this study at scale $(150 \mathrm{~kg} / \mathrm{h})$ are in direct agreement with data obtained in batch laboratory scale experiments, and show that microwave heating processes are fundamentally scalable. It is shown that there is a trade-off between the efficiency of organic removal and the power distribution, and applying the power in a single stage was found to be $20-30 \%$ more energy efficient but the overall degree of organic removal is limited to $60 \% .75 \%$ removal was possible using two processing steps in series, but the organic removal is ultimately limited by the amount of power that can be safely and reliably delivered to the process material. The concept presented in this work is feasible when $75 \%$ organic removal is sufficient, and could form a viable industrial-scale process based on the findings of this study.

KEYWORDS: Microwave Processing; Contaminated Soil; Remediation; Hydrocarbons

\section{INTRODUCTION}

Many papers are published each year reporting promising microwave experiments in a plethora of applications, and yet the conversion of these to industrial scale microwave processes is low [1]. A lack of data from pilot and demonstration systems often prevents successful scale-up because the technical risks have not been fully evaluated and mitigated. In recent years, a number of pilot-scale and commercial prototype systems have been developed for applications that exploit the selective and volumetric heating benefits offered by microwave heating [2-4]. These processes are continuous, and have been developed via multidisciplinary collaboration between experts in solids handling, process engineering and electromagnetics. There are numerous engineering challenges that need to be overcome in order to successfully implement the scale-up of microwave heating processes, in part because the 'engineering science' within this field is not fully established. One such challenge relates to electric field breakdown, or arcing, which can result in very high localised temperatures and damage to the microwave and materials handling systems. Arcing occurs in gases as they can only sustain an electric field of relatively low intensity compared to liquids and solids. For example, the breakdown voltage in air is $33 \mathrm{kV} / \mathrm{cm}$ at ambient conditions, compared to $30,000 \mathrm{kV} / \mathrm{cm}$ for water [5]. The breakdown voltage reduces significantly at higher temperatures and when droplets/particulates are present within the gas [6]. The physics of arcing is well understood, but the mitigation of this effect in continuous processing systems often presents the final barrier in moving from prototype to full scale commercial implementation. 
This study reports the development and evaluation of a continuous, pilot-scale microwave processing system for the removal of hydrocarbons from solid materials, and highlights the key challenges in operating at scale and the mitigating steps that can be employed. There are numerous applications to which this process can be applied, however the specific focus of this study is on using hydrocarbon contaminated soils as model feedstocks for process evaluation.

The UK government has estimated that around 300,000 hectares, or $2 \%$ of the UK land mass can be classed as contaminated. This contamination can take the form of heavy metals, asbestos, radionuclides and organic compounds [7]. Sites deemed to have unacceptable soil contaminant concentrations can undergo risk management, involving removal of the source, interruption of exposure pathways (containment) or management of receptor behaviour, or some combination of the three [8]. In situ remediation options often involve soil vapour extraction (SVE) [9], sometimes allied to heating methods such as six phase soil heating or steam injection to increase volatilisation, or target less volatile contaminants [10]. More aggressively, a range of oxidising agents, such as ozone, persulphates or peroxides may be injected into the subsurface to treat both soil and groundwater [11]. Biodegradation methods, particularly for hydrocarbon contamination, can also be used for in situ treatment [12]. Ex situ methods include mechanical and thermal treatment. Mechanical processing usually involves soil washing [13]. Thermal desorption may also be used for some of the most grossly contaminated sites, such as former gasworks, and involves heating the soil to between 100 and $800^{\circ} \mathrm{C}$ to volatilise heavy organics [14]. This is generally confined to large, centralised processing facilities and may be unsuitable for the remediation of smaller-scale sites.

Microwave heating has previously been shown to remove organic contaminants from soils [15], and may be a viable alternative to conventional thermal desorption processes. Microwaves heat selectively and volumetrically. This unconventional heating mechanism gives rise to a range of potential benefits in the processing of contaminated soils: heating rates can be three orders of magnitude higher than conventional processes [6], leading to smaller (potentially portable) processing equipment and flexible operating schedules; microwaves target water that is bound within the soil, and this leads to the ability to process soils containing significant amounts of clay minerals [16], which are difficult to process using conventional soil remediation techniques, principally due to their low hydraulic conductivity [17].

Microwave processing of contaminated soils has the potential to offer step change improvements in soil remediation. Previous studies have shown that Poly-Aromatic Hydrocarbons (PAHs) could be efficiently removed from two contaminated soils samples [15] and Horikoshi et al [18] showed that significant removal of trichloroethylene was possible from a model soil material. The levels of organic removal depend on the electric field intensity generated within the microwave applicator, and the subsequent power density within the heated phase(s) of the soil. High electric field intensities lead to high power densities, and correspond to higher levels of organic removal than low field intensities.

\subsection{Underpinning Mechanism}

Previous work identified that the mechanism of organic removal from soil using microwaves arises from selectively heating the aqueous phase and not directly the organic contaminant phases themselves $[2,3,16]$. Table 1 shows the dielectric properties of a number of relevant materials. The minerals presented could typically be expected to be found in a soil sample. The dielectric loss $(\varepsilon ")$ can be considered a measure of a materials 
ability to dissipate absorbed microwave energy as heat. The higher the dielectric loss, the better the material will heat in an applied field. Materials with a loss of $<0.005$ can be considered microwave transparent [6].

Table 1: Dielectric Properties of materials at $25^{\circ} \mathrm{C}$ and $2.45 \mathrm{GHz}$ (adapted from [2])

\begin{tabular}{|c|c|c|}
\hline Material & Dielectric Constant $\left(\varepsilon^{\prime}\right)$ & Dielectric Loss $\left(\varepsilon^{\prime \prime}\right)$ \\
\hline Water & 77 & 0.002 \\
\hline Fuel Oil & 2.0 & 0.001 \\
\hline Quartz & 3.8 & 0.005 \\
\hline Mica & 1.6 & 0.002 \\
\hline Feldspar & 2.6 & \\
\hline
\end{tabular}

So in a mixture of bulk soil, hydrocarbon contaminants and water, it is the water phase that will be heated selectively through the volume of the solid. Providing that sufficient power density is achieved in the soil, rapid microwave heating converts the water in the soil to steam, which then strips the organic contaminants from the soil. This effect has also been observed in microwave heating of contaminated drill cuttings [2, 3] and oil sands [16], which are structurally similar to contaminated soils, given they contain mineral matter, oil and water. Previous work reported in [16] has shown that while the bulk temperature of a hydrocarbon contaminated soil remains around $100^{\circ} \mathrm{C}$, PAHs with boiling points $218^{\circ}-400^{\circ} \mathrm{C}$ are completely removed and in excess of $90 \%$ those with a boiling point above $400^{\circ} \mathrm{C}$ are removed. This can be attributed to selective heating of the water phase, generating localised temperatures in the soil structure sufficient to entrain hydrocarbon contaminants into the exhaust vapour. In the work reported in [16], a lab-scale single mode batch system was shown to be effective for extracting naturally occurring hydrocarbons from oil shales. However, this system used only a relatively low power $(3 \mathrm{~kW})$ and small samples masses $(150 \mathrm{~g})$.

The aim of this study is to build on previous laboratory-scale reports and design and test a pilot scale continuous microwave treatment process using soils as a model feedstock, and asses the feasibility of developing the concept to an industrially relevant scale at 2-3 tonnes per hour. The objectives of this work are:

1. Characterise the electric field distribution within the microwave processing system, and understand the interaction of the soil feed stocks with the electric field

2. Establish the processing conditions for stable process operation, and determine the process efficiency under these conditions

3. Investigate the feasibility of in-series processing to improve process robustness, and understand the impact on process efficiency.

\section{MATERIALS AND METHODS}

\subsection{Soil sampling}

Four bulk soil samples were obtained from contaminated industrial sites within the UK. The samples were transported from site in skips in 2-tonne batches, and mixed for 4 hours using a Meyer 6002 soil mixer, which can act as both a mixer and a feeding system. After the mixing process, the mixer was set into its feeding position and allowed to discharge $100 \mathrm{~kg}$ of material. A sample of homogenised material was taken using the cone and quarter method [19] to $5 \mathrm{~kg}$, following by riffling to 5 grams for compositional analysis. 


\subsection{Sample analysis}

The water content and total organic content were the parameters used to characterise the performance of the system under trialled operating conditions. The water content was established using the Dean \& Stark method [20], which involved reflux distillation with Toluene followed by the subsequent separation and recording of the immiscible water phase. The organic content was determined by extracting the organic phase from the soil matrix using Soxhlet extraction with Dichloromethane (DCM). The extracted organics were further separated from the mixture after evaporation of the DCM under ambient conditions, a process that takes 48 hours. All analysis was carried out in triplicate, and the results expressed as an average of the three readings. The dielectric properties of the soil samples were determined at $2.45 \mathrm{GHz}$ using a cavity perturbation technique [6, 21].

\subsection{Soil Composition}

The starting composition of the four soils used in the study is shown in Table 1 in terms of their water and total organic contents. The results presented are an average of four measurements for each soil. The standard deviation for both the water and total organic content is low, indicating that all the soils prior to processing were effectively homogenised, so subsequent analysis is representative of the bulk soil. The organic contaminant fraction comprises of a mixture of hydrocarbons typically associated with post-industrial sites found in the UK. Namely, Poly-Aromatic hydrocarbons (PAHs); Benzene, Toluene, Ethly Benzene and o-, m-, p- xylenes (BTEX) compounds.

Table 2: Water and total organic content of the four soil samples used in the experimental programme

\begin{tabular}{|c|c|c|c|c|}
\hline \multirow{2}{*}{$\begin{array}{c}\text { Feedstock Sample } \\
\text { ID }\end{array}$} & \multicolumn{2}{|c|}{ Water Content \%(w/w) } & \multicolumn{2}{c|}{ Total Organic Content \%(w/w) } \\
\cline { 2 - 5 } & Average & Standard Deviation & Average & Standard Deviation \\
\hline 1 & 15.99 & 0.12 & 2.52 & 0.05 \\
\hline 2 & 8.37 & 0.09 & 1.50 & 0.04 \\
\hline 3 & 13.4 & 0.13 & 1.44 & 0.04 \\
\hline 4 & 16.05 & 0.10 & 1.48 & 0.05 \\
\hline
\end{tabular}

The ability of each soil to heat in an applied microwave field at a given frequency can be evaluated by calculating its loss tangent (tanס), which is the ratio of the dielectric loss to the real part of the permittivity. The cavity perturbation technique $[6,21]$ was used to measure the loss tangent as a function of temperature. The average loss tangent based on triplicate measurements of the four test soils between 20 and $300^{\circ} \mathrm{C}$ at $2.45 \mathrm{GHz}$ is presented in Figure 1. 


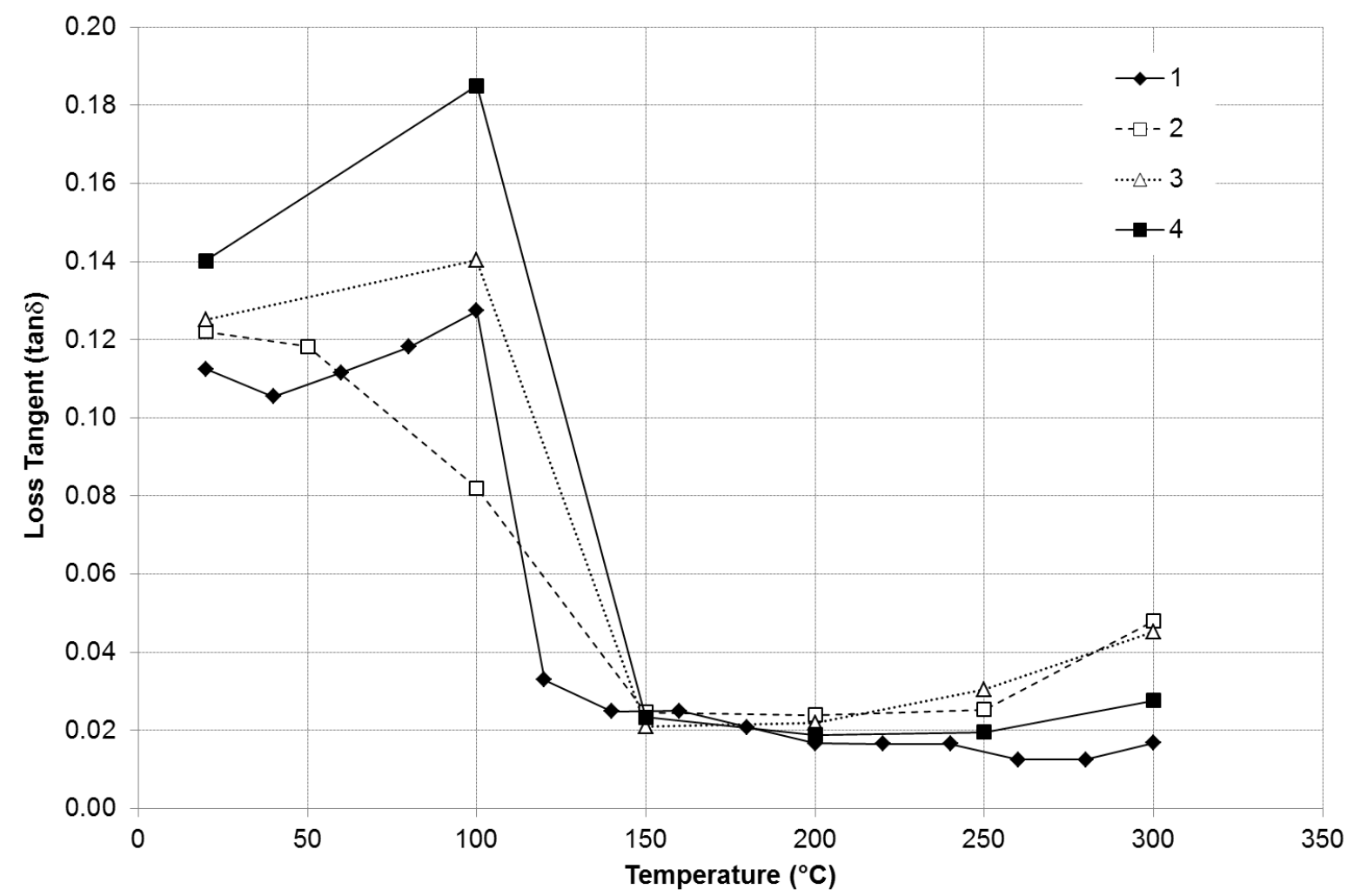

Figure 1: Loss tangent of the four test soils measured as a function of temperature using the cavity perturbation technique.

A higher loss tangent indicates a greater ability for a material to be heated in an applied microwave field. Materials with loss tangents of $>0.1$ are considered to be good candidates for microwave heating [6]. Figure 1 shows that at temperatures below $100^{\circ} \mathrm{C}$, all the soils can be classed as good heaters. The loss tangent then drops rapidly above $100^{\circ} \mathrm{C}$. This corresponds to the evaporation of free water and indicates that it is the water that will be the primary heated phase within the soils. These results indicate that the residual organic and mineral content is relatively microwave transparent, and this is consistent with previous studies [22]. The data from Figure 1 suggest that hydrocarbon removal will be not be dependent on direct energy absorption, but rather on the physical properties of the hydrocarbon phases, their distribution within the soil matter and the mass transfer characteristics of the soil $[15,23]$.

\section{DESIGN OF A CONTINUOUS MICROWAVE PROCESS}

Previous studies in this field use off-the-shelf batch microwave equipment for small scale tests [23-25]. This work is valuable for identifying some of the key effects, heating mechanisms and the influence of the main process variables. Laboratory based systems cannot, however, be easily adapted for scale-up as they are not compatible with bulk materials handling systems. They can also lead to large temperature distributions and subsequent uneven heating of the target materials during processing. Scale-up must therefore be achieved using a continuous processing approach.

There are numerous options for continuous processing of solids using microwave heating, but common to all is that a bulk solids handling system must be used to transport the material through a microwave applicator. The applicator contains the required electric field distribution, the design of which must not only be compatible with 
the materials handling system, but also consider hot gas removal. A choke is required in conjunction with the applicator, to allow the process materials to pass in and out of the applicator, but contain the electric field within the system so that the process complies with regulatory requirements set out in health and safety (H\&S) and Electromagnetic Compatibility (EMC) legislation [25]. Materials handling options range from gravity flow and pneumatic conveying to vibratory feeders and conveyor belts. The latter was identified as the most appropriate method of transporting the soil through the applicator due to the simplicity of design which had proven itself suitable in similar studies [3].

There are several examples of conveyor belt concepts that are successfully used for continuous microwave processing, particularly in the food industry [26]. In many cases, the belt passes through a large multimode microwave oven. However, these applicators are not appropriate for hydrocarbon-containing solids as their inherent low electric field strengths do not promote the high heating rates that have been shown to be necessary in laboratory scale studies [2, 15, 27, 28]. In addition, heterogeneous electric field patterns lead to limited and uneven processing [2]. An applicator that supports a much higher electric field than a multimode cavity is required. An example of a single mode applicator able to support high electric field strengths is a tunnel applicator [27]. The electric field distribution within such an applicator has been characterised in previous studies and been shown to be successful for treating oil contaminated drill cuttings [27].

Microwave heating was carried out using a system that was specifically designed and constructed for the treatment of hydrocarbon-containing solids, a schematic of which is shown in Figure 2.

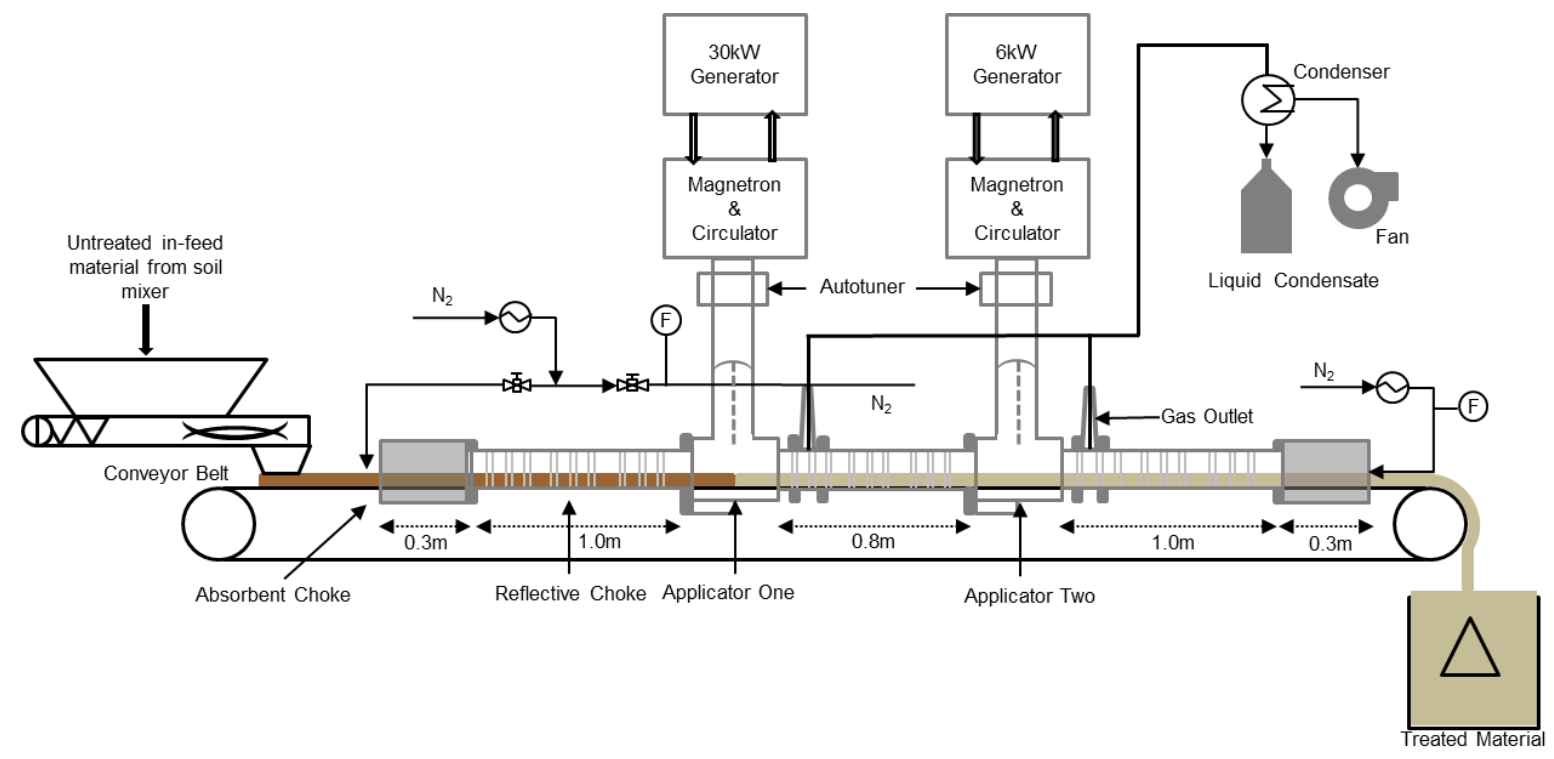

Figure 2: Schematic of continuous microwave treatment system used in this study.

A basalt-fibre based conveyor belt was used to transport the soil through two identical microwave applicators arranged in series. The belt material comprised of woven fibres made from extruded basalt, and supplied by Sudaglass Fiber Technology, Houston USA. The material was manufactured to the appropriate length, having a width of $300 \mathrm{~mm}$, and joined by stitching with glass-fibre thread. The belt was formed into a trough-shape to prevent the soil from sticking to the sides of the microwave applicator or from falling off the edges of the belt. Nitrogen was supplied as a sweep gas at a flowrate of $20 \mathrm{~m}^{3} / \mathrm{hr}$ to inert the system and to carry the evolved process vapours to the extraction system. It was introduced to each end of the microwave chocking structure and a small positive pressure applied down the waveguide to prevent ingress of steam and organic vapours into the 
microwave hardware. An extraction fan was used to draw evolved steam, organic vapours and nitrogen out of the applicator and through a shell and tube condenser cooled with water. The measurement of temperature in microwave based systems is challenging. It often relies on Infra-Red, which only reads the material surface temperature, or fibre optic technology which is inherently fragile and not suitable for continuous systems. As such temperature measurements were not recorded in the system. The focus was on defining operational parameters of the system in terms of applied power and hydrocarbon removal

Mixed soil was fed onto the conveyor belt via a twin-screw feeder to ensure a uniform feed profile. The screw speed was set to give a discharge rate of $150 \mathrm{~kg} / \mathrm{hr}$ and kept constant for all tests. The screw feeder was positioned directly above the troughed belt, and below a feed hopper with a 200 litre capacity. Once on the belt, a series of adjustable gauges were used to maintain the maximum level of soil, and to smooth out any fluctuations in the feed profile. The bed depth was primarily controlled by adjusting the speed of the conveyor belt in relation to the speed of the twin-screw feeder. The bed depth of soil on the belt was maintained at $30 \mathrm{~mm}$ for this study.

The microwave applicators are transverse wave E-field designs with a self-cancelling reflection step, the principles of which are given by Metaxas and Meredith [26]. Inhomogeneity of heating is a characteristic of multimode systems where the microwave applicator supports a number of modes that may both cancel or reinforce each other. However, the applicator used in this work is a TE applicator, which results in an even electric field across its width. The feedstock was passed along a tunnel, with the microwaves entering the tunnel from a waveguide transition positioned above the belt. The reflection step was positioned below the belt. This device was off-set from the centre-line of the waveguide in order to create three modes within the applicator, an illustration of this concept in given in a previous publication [28]. The design is based on the average dielectric properties of the soil samples to be treated, and yields a uniform electric field across the width of the applicator. Three overlapping modes are formed in the vertical dimension. These produce a greater degree of heating uniformity throughout the depth of the soil, than if no reflection step was present. The residence time of the soil within the applicator was 4 seconds at a constant throughput of $150 \mathrm{~kg} / \mathrm{hr}$. Gas extraction points were located immediately adjacent to the applicator on the down-stream side. Based on the measured dielectric properties, COMSOL Multi-Physics software was used to determine the distribution of the electric field within the applicator and the power density within the process material. Figure 3 shows the dimensions of the applicator used in this study, and Figure 4 and Figure 5 show respectively the electric field and power density distributions within the applicator containing soil sample 1 . 


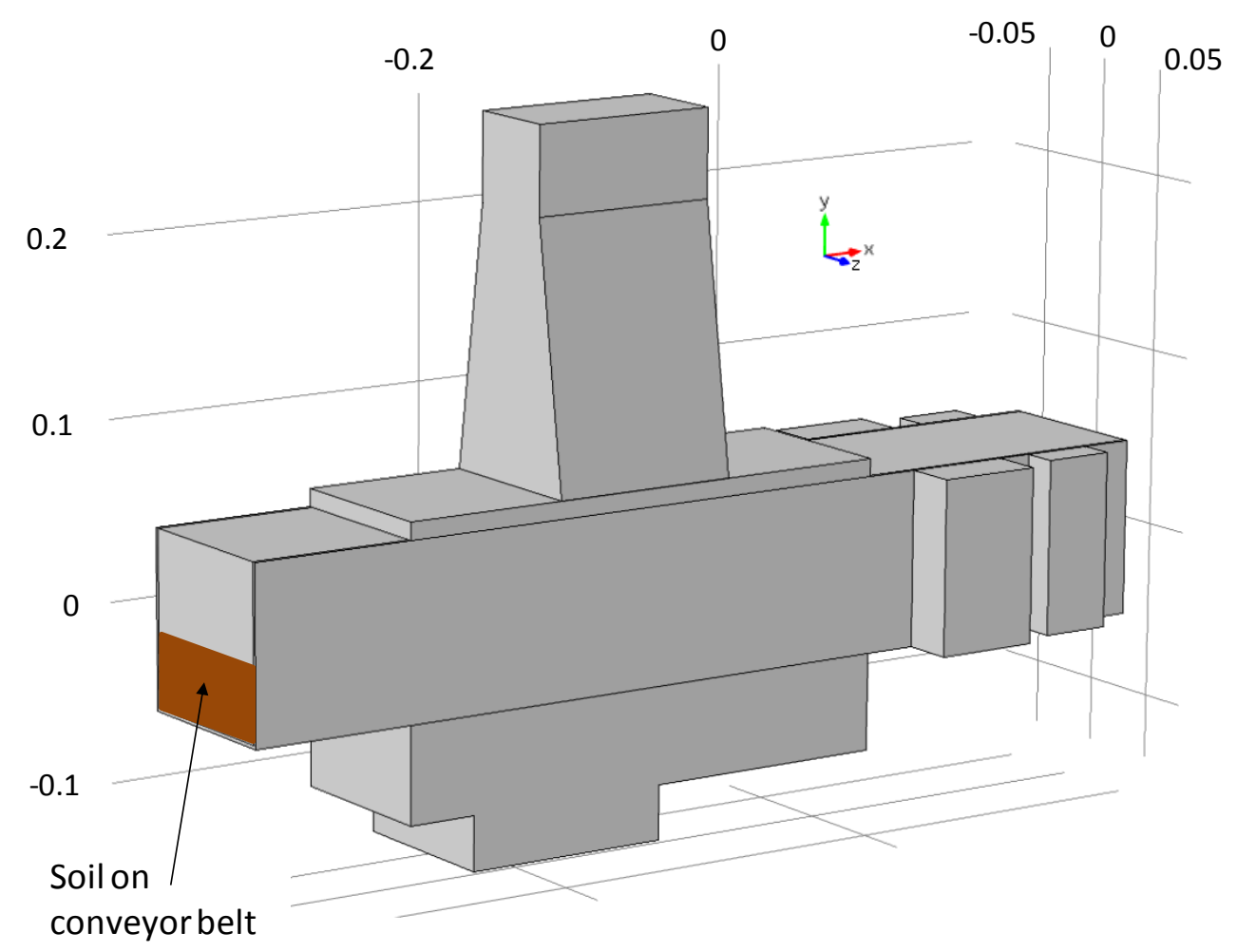

Figure 3: 3D Layout and dimensions of microwave applicator. Grid dimensions are in metres.

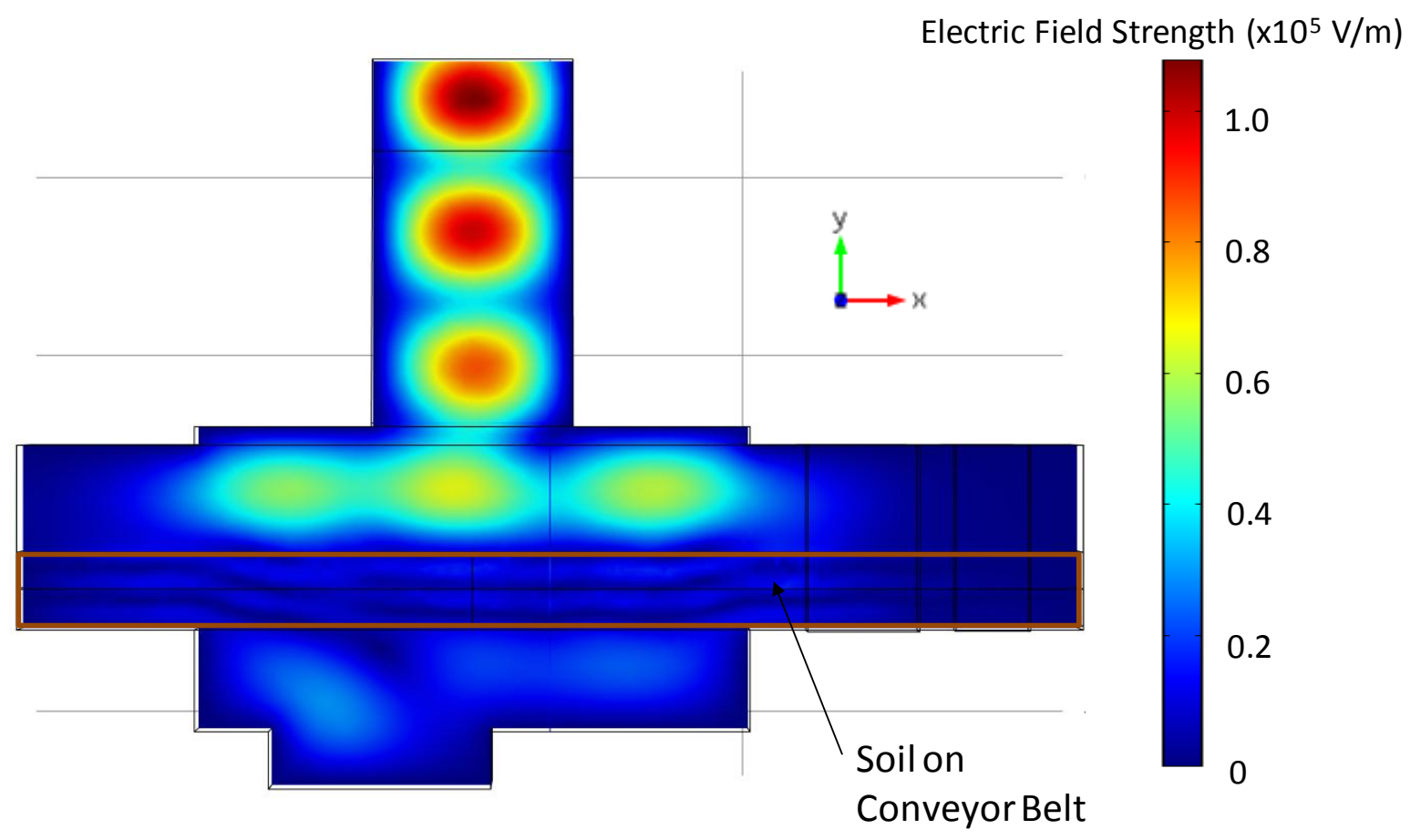

Figure 4: Electric field strength in the vertical plane on the centre axis of the applicator. Applied power $=15 \mathrm{~kW}$. The soil on the conveyor belt is located within the highlighted rectangular section with a bed depth of $30 \mathrm{~mm}$. 


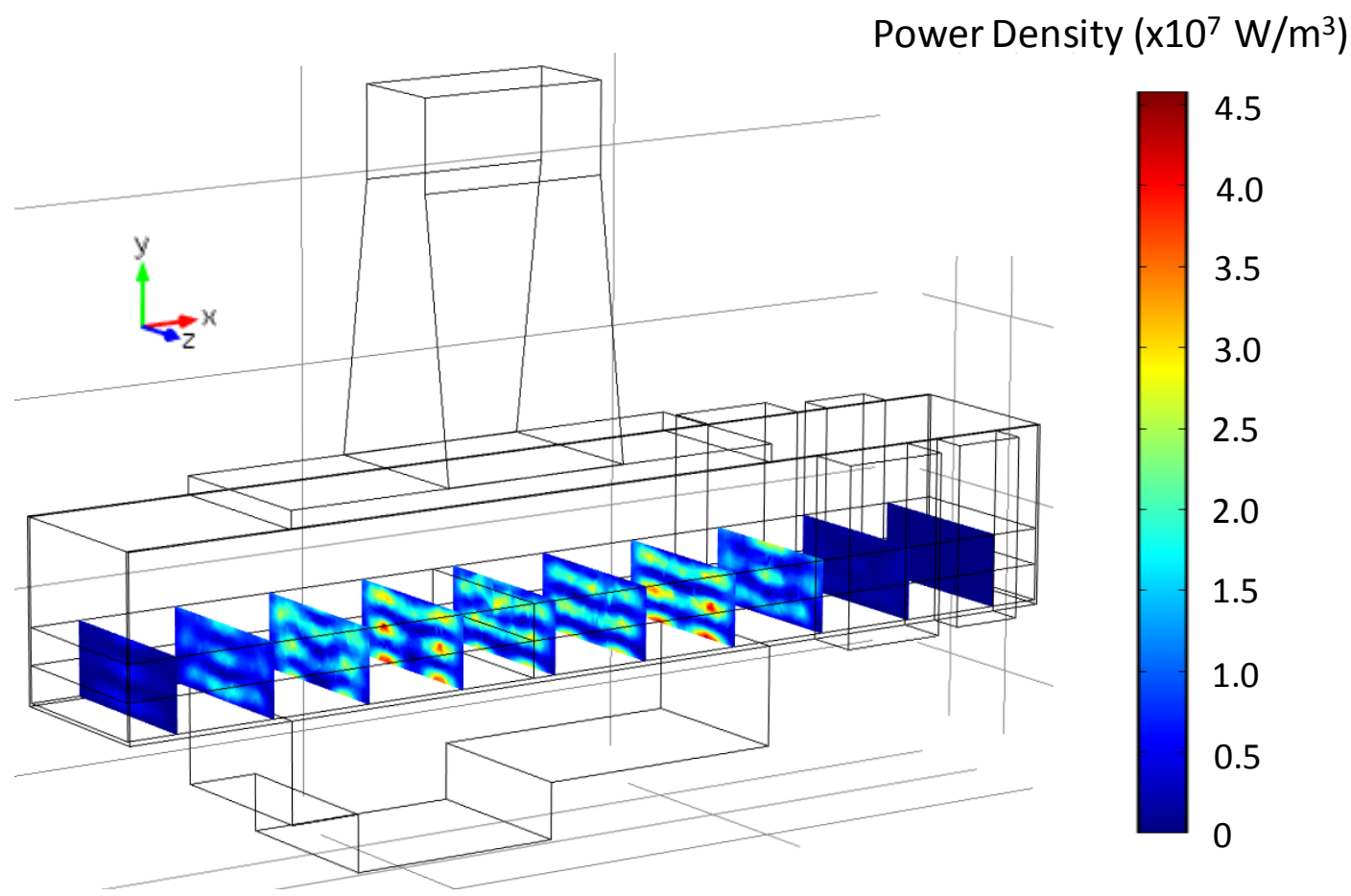

Figure 5: Power density distribution within 10 vertical planes of soil along the length of the applicator. Applied power $=15 \mathrm{~kW}$.

Reflective chokes were used to prevent microwaves propagating along the length of the conveyor and into the wider environment. A choke section was included in between the two applicators, to minimise power transfer between the separate waveguides. A further choke was positioned upstream of the first applicator and downstream of the second applicator. The three reflective chokes were corrugated structures designed to provide attenuation levels of $-60 \mathrm{~dB}$. Absorbent chokes were also included at each end of the conveyor as an extra safety measure. These chokes were lined with microwave-absorbent carbon-foam, giving total attenuation levels of $-85 \mathrm{~dB}$ when fully loaded with processed soil. The chokes were designed using CONCERTO, a finite difference time domain software package. Following design, the choke structures were cold tested using an Agilent E5061B Vector Network analyser and appropriate waveguide to coaxial transitions. In each case the choking structures were shown to perform up to $-40 \mathrm{~dB}$ better than designed.

The waveguide transitions on each applicator were connected to the microwave generators using a series of waveguide components. A Sairem automatic E-H tuner was positioned in a bend above the microwave applicator to dynamically match the impedance of the generator and transmission line to the cavity and load. This compensates for changes in the dielectric properties of the feedstock on the belt during heating. It also ensured that the optimum amount of power supplied by the generators was absorbed by the process material at any one time.

Instrumentation was installed to ensure that the system could be operated safely and reliably. Reflected power was monitored for each applicator and used to adjust the applied power. Microwave leakage sensors were positioned at the end of the absorbent choke sections and hard-wired to the microwave generators. A complete system shut-down was enacted if the sensors detected leakage levels $>0.5 \mathrm{~mW} / \mathrm{cm}^{2}$. All sensors were designed to fail safe. 


\section{CONTINUOUS PROCESSING}

All four soils were processed through the system at a constant throughput of $150 \mathrm{~kg} / \mathrm{h}$ for five minutes during each run. Longer runs were possible, but the mass of the bulk untreated soils had to be preserved to complete all the tests required.

The microwave power levels were varied systematically, and the remaining organic content of the soils was determined for each condition. These tests were performed using a single microwave applicator at a constant throughput of $150 \mathrm{~kg} / \mathrm{h}$, and the results are shown in Figure 6.

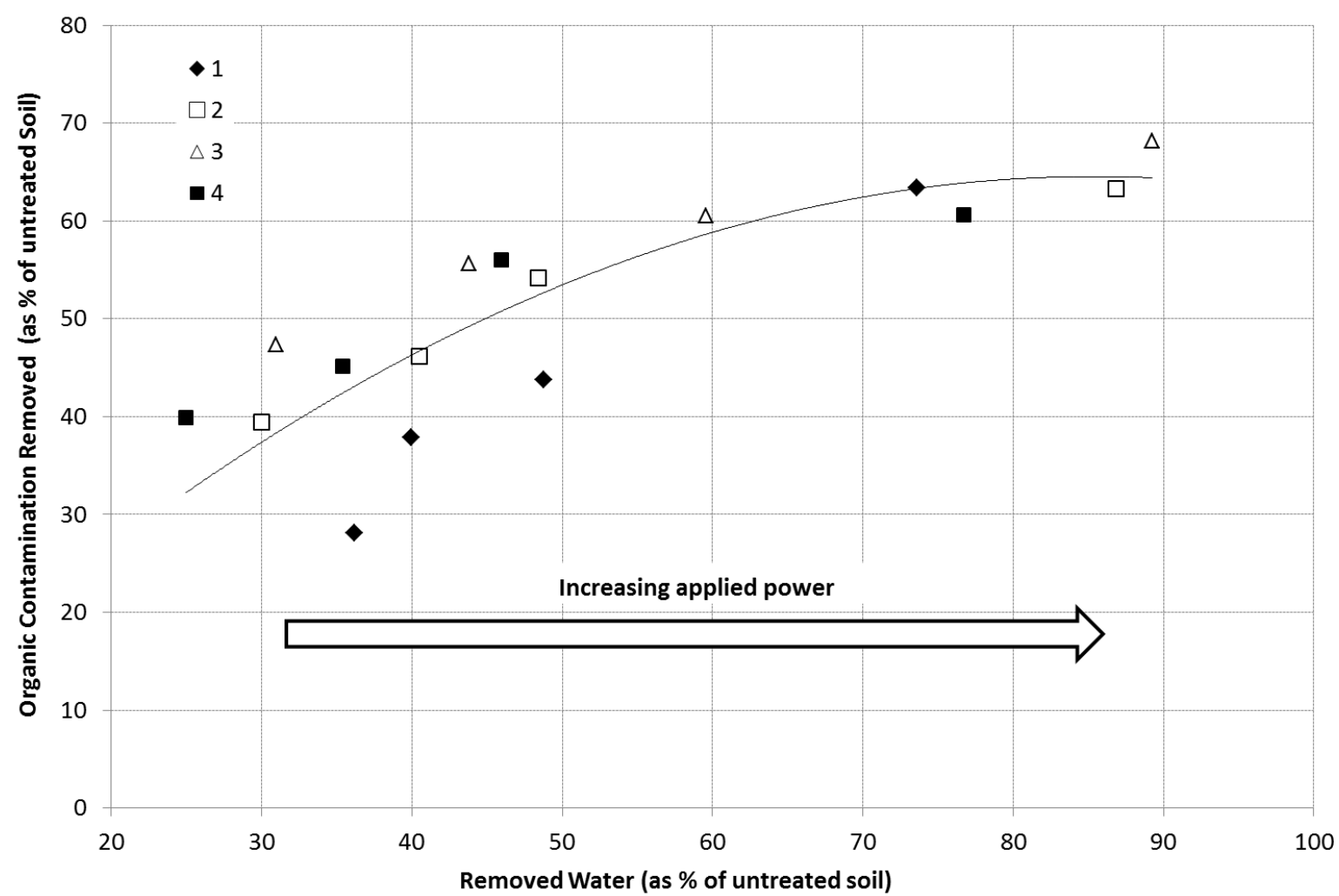

Figure 6: Relationship between the amount of organic material and water removed from the soil as a function of power at constant throughput of $150 \mathrm{~kg} / \mathrm{h}$ using a single applicator

Figure 6 shows that as the applied power is increased the total amount of organic contamination removed also increases. The greatest change in organic content was observed in soil 1, which had a starting extracted organic content of ca. $25 \mathrm{~g} / \mathrm{kg}$ compared to ca. $15 \mathrm{~g} / \mathrm{kg}$ for the others. Increasing the applied power had the effect of reducing the extracted organic content closer to that of the other soils, with an applied power of $15 \mathrm{~kW}$ yielding a very similar endpoint for all of the soils tested. This suggests that as the levels of organic contamination increase, so higher powers will be required. The microwave hardware used for this study could achieve a maximum power output of $30 \mathrm{~kW}$, however power levels above $15 \mathrm{~kW}$ lead to arcing and unstable/unsustainable operation for all four samples studied.

Increasing the applied power, results in more of the water being removed and as per the effect on organic content. Differences between removal rates for the four soils are likely to result from their particular heat and mass transfer characteristics. It is known from laboratory scale studies that hydrocarbon removal takes place indirectly due to heating of the water phase, and a number of different mechanisms have been proposed [15, 29, 30]. 
There is a correlation on processing between the amount of the organic fraction removed and the removal of water from the soil. This tends to a maximum at about $60-70 \%$ residual organics and $70-90 \%$ removed water. The highest removal rates were attained at the highest applied powers, just below the limit of process stability (in terms of product arcing). However, up to $30-40 \%$ of the extracted organic phases in the starting material remain in-situ after treatment. This threshold composition applies to all four soils tested. A number of factors could be attributed to this behaviour; the first is the distribution of the water and organic material through the soil. The results of the compositional analysis show that the soils are effectively mixed at the start of the process. However, water on or near the surface is likely to evaporate without significant interaction with the organic phase. This could result in a drying effect, without the corresponding removal of the organic fraction. In addition to this, not all the water was driven off. Levels of organic removal may have been increased if all of the water could be used to entrain the organic phases, and Figure 6 shows that the water content in processed samples varies from $2-6 \%$. If the remaining water could be removed by using higher power levels then it is likely that more of the organic phase could also be removed, however it was not possible to process any of the soils at power levels above $15 \mathrm{~kW}$ as arcing was observed to limit the stability of these experiments.

The natural soil composition itself may play a part. Soils by their nature contain a fraction of Soil Organic Matter (SOM). Work by Hawthorne et al [31] showed that when using Soxhlet extraction to remove the contaminant phase from the soil solids, a fraction of the SOM is also co-extracted from the soil matrix. They reported that the composition of the extracted phase was $1 / 4$ to $1 / 3$ of bulk SOM, with the remainder being PAH contamination. Soxhlet extraction was used because it could be done relatively quickly, immediately after processing, and a number of analyses could be conducted in parallel. The microwave process for decontaminating the soil may well be more (or less) efficient that the data suggests, as actual residual organic contamination may not necessarily be that quantified by Soxhlet extraction. A more detailed analysis of the actual composition of the vapour phase removed using the microwave process, as well as that removed from the bulk treated soil using Soxhlet extraction, would show whether this is the case and is a recommendation for further work.

In order to increase the organic removal efficiency by driving off the remaining $10-30 \%$ water, the use of two identical applicators in series was investigated. This allows the energy dose to be increased without reducing throughput or having to use power levels above the $15 \mathrm{~kW}$ threshold. Trials were conducted with soil 1 , using two applicators in series at a constant throughput of $150 \mathrm{~kg} / \mathrm{h}$. The power level was varied in each applicator using a maximum applied power of $22.5 \mathrm{~kW} ; 15 \mathrm{~kW}$ in applicator 1 and $7.5 \mathrm{~kW}$ in applicator 2 . The power combinations used are presented in Table 3.

Table 3: Power combinations used comparing one vs two microwave applicators

\begin{tabular}{|c|c|c|c|}
\hline \multirow{2}{*}{$\begin{array}{c}\text { Single } \\
\text { Applicator }\end{array}$} & \multicolumn{2}{|c|}{ Two Applicators } \\
\cline { 2 - 4 } & 5 & No.1 & No.2 \\
\hline \multirow{3}{*}{$\begin{array}{c}\text { Applied Power } \\
(\mathrm{kW})\end{array}$} & 10 & 5 & 5 \\
\cline { 2 - 4 } & 12.5 & 10 & 7.5 \\
\cline { 2 - 4 } & 15 & 10 & 5 \\
\cline { 2 - 4 } & - & 15 & 7.5 \\
\hline
\end{tabular}


The results of using these power combinations on extracted organic content expressed as a function of energy absorbed (kWh/t of soil processed) is shown in Figure 7.

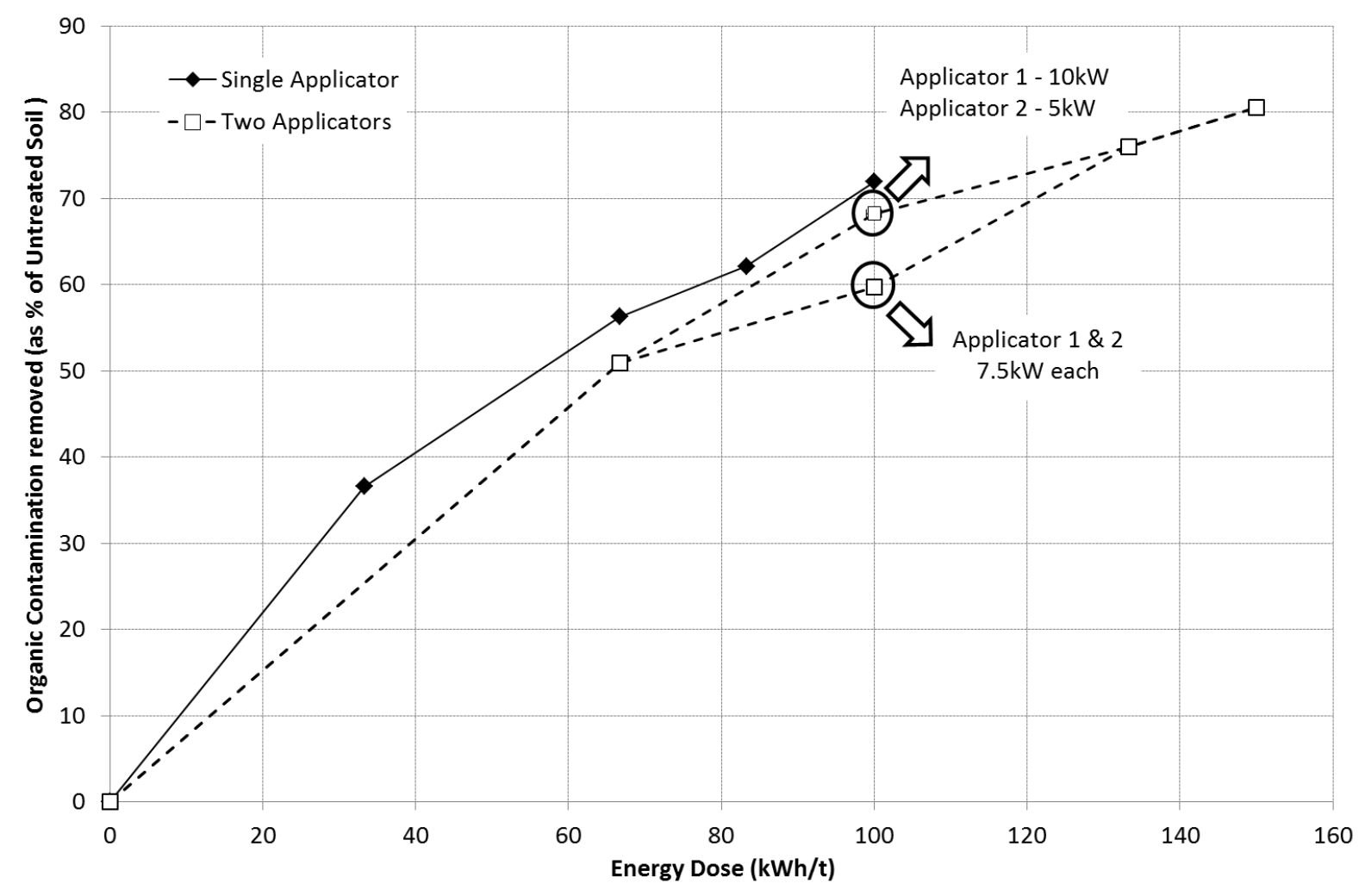

Figure 7: Removal of contamination from soil 1 after processing using one and two applicators and varying applied powers at a throughput of $150 \mathrm{~kg} / \mathrm{h}$

The use of two applicators allowed for higher total powers to be applied without the process becoming unstable due to arcing. The maximum residual extracted organic content at an energy dose of $150 \mathrm{kWh} / \mathrm{t}$ was $5.8 \mathrm{~g} / \mathrm{kg}$ compared to $7.1 \mathrm{~g} / \mathrm{kg}$ at $100 \mathrm{kWh} / \mathrm{t}$ for a single applicator. Figure 7 shows that using a second applicator in series does allow more of the organic phase to be removed, however the extra energy requirements are significant for relatively modest improvements in organic removal.

The maximum applied power in the second applicator was $7.5 \mathrm{~kW}$. Increasing the power beyond this level led to process arcing and high reflected powers. This is indicative of low amounts of microwave absorbent phase (water) in the soil entering the second applicator, but does confirm that the remaining water after processing through the first applicator can be used in the second to further reduce the organic content. Of note is that the residual organic content is dependent upon the combination of applied power, rather than the net power from both. It can be seen in Figure 7 that using a power of $7.5 \mathrm{~kW}$ in each applicator leaves more organic material in the soil compared to applying $10 \mathrm{~kW}$ in the first and $5 \mathrm{~kW}$ in the second, despite the energy dose being the same. For an energy dose of $100 \mathrm{kWh} / \mathrm{t}$, the best result is obtained using $15 \mathrm{~kW}$ applied in a single applicator. This shows that the process benefits from using the highest possible applied power from a single applicator, rather than spreading it across two in series, which has been shown to decrease the process efficiency. This result can be understood by considering Eq. 1, which shows that heating rate is proportional to power density [27]: 
Equation 1

$$
: \frac{\Delta T}{\Delta t}=\frac{P d}{\rho C p}
$$

where: $T$ is temperature, $t$ is time, $P d$ is power density, $\rho$ is density in and $C p$ is heat capacity

The fastest heating rate is realised by achieving the highest power density in the process material. When two applicators are used in series, the soil is heated in the first then has to move through the choking structures, before entering the second. At a throughput of $150 \mathrm{~kg} / \mathrm{h}$, there is a delay period of $16 \mathrm{~s}$ between the soil exiting applicator 1 and entering 2. During this time the energy absorbed by the water is dissipated to the mineral matter and organic phase. This redistribution of heat away from the aqueous phase will not necessarily then be used in the extraction process, effectively being lost to the soil matrix. Applying the equivalent power in a single event minimises heat transfer to the bulk solid, yielding a more efficient process. In addition, rapid temperature rise of the water increases the propensity for superheating. This can yield increased capillary pressures within the soil bed that may drive the aqueous phase through the soil matrix as it escapes out to the flue gas. This further increases the interaction of the aqueous and hydrocarbon phases as well as exposing contamination that may have been sequestered into the soil matrix and not exposed on particle surfaces. Finally, the maximum temperature of the superheated water increases with heating rate, and this enables removal of heavier organic compounds.

Using two applicators in series allows more power to be delivered to the process material, and is a viable strategy to mitigate arcing at high power levels. The compromise for this improvement in process robustness is the overall efficiency of the system, and Figure 7 shows that $20-30 \%$ more energy is required to achieve the same residual organic content with two applicators in series, compared to a single microwave applicator. Even with two applicators there is still a limit to the total net power that can be applied, which in this case was $22.5 \mathrm{~kW}$. This has significant implications in applications where very high levels of organic removal are required, and in this case it is unlikely that a belt-conveyor system such as the one used for this study would be a viable option due to the limitation in the applied power that can be utilised. In applications where lower levels of organic removal are required, the data reported here shows that the conveyor belt concept could be a viable option for microwave processing, and that utilising two microwave applicators in series could improve the process robustness and operability provided that the energy penalty is acceptable. In terms of operating cost, assuming an energy dose of $150 \mathrm{kWh} / \mathrm{t}$ is sufficient to remediate the soil and a UK industrial electricity tariff of $9.55 \mathrm{p}$ per $\mathrm{kWh}$ [32], yields $£ 14$ per tonne of material processed.

\section{CONCLUSONS AND RECOMMENDATIONS FOR FURTHER WORK}

A continuous conveyor-belt processing concept using microwave heating was shown to be viable for the removal of organics from four contaminated soils. The findings of this study are in agreement with data obtained in batch laboratory scale experiments, and show that microwave heating processes are scalable. Arcing was found to limit the robustness of the processing system, and a processing strategy to limit arcing by distributing the power input was shown to be feasible. There is a trade-off between the efficiency of organic removal and the power distribution, and applying the power in a single stage was found to be $20-30 \%$ more energy efficient but the overall degree of organic removal is limited. The concept presented in this work is feasible when organic removal 
below a certain threshold (in this case around $75 \%$ ) is sufficient, and could form a viable industrial-scale process based on the findings of this study. However, in cases where $>75 \%$ organic removal is required then the beltconveyor concept is not feasible. Future work will focus on alternative processing strategies that allow higher power delivery whilst maintaining robustness by preventing or mitigating arcing, thereby allowing higher levels of organic removal to be achieved safely and reliably.

\section{ACKNOWLEDGEMENTS}

We wish to thank Shanks Waste Management for providing the soil samples. 


\section{REFERENCES}

[1] A. Buttress, A. Jones, S. Kingman, Microwave processing of cement and concrete materials-towards an industrial reality?, Cement and Concrete Research 68 (2015) 112-123.

[2] J. Robinson, S. Kingman, O. Onobrakpeya, Microwave-assisted stripping of oil contaminated drill cuttings, Journal of environmental management 88 (2008) 211-218.

[3] I.S. Pereira, J.P. Robinson, S.W. Kingman, Effect of Agglomerate Size on Oil Removal during Microwave Treatment of Oil Contaminated Drill Cuttings, Industrial \& Engineering Chemistry Research 50 (2011) 9727-9734. [4] P. Rattanadecho, N. Suwannapum, B. Chatveera, D. Atong, N. Makul, Development of compressive strength of cement paste under accelerated curing by using a continuous microwave thermal processor, Materials Science and Engineering: A 472 (2008) 299-307.

[5] A.M. Howatson, An introduction to gas discharges, Pergamon press Oxford1965.

[6] R.J. Meredith, Engineers' handbook of industrial microwave heating, IET1998.

[7] Environment Agency, Dealing with contaminated land in England and Wales https://www.gov.uk/government/uploads/system/uploads/attachment_data/file/313964/geho0109bpha-e-e.pdf, 2009.

[8] P. Thomas, N. Charles, Model Procedures for the Management of Land Contamination, Environ. Monit. Assess 17 (2004) 33-49.

[9] J.T. Albergaria, M.d.C.M. Alvim-Ferraz, C. Delerue-Matos, Remediation efficiency of vapour extraction of sandy soils contaminated with cyclohexane: Influence of air flow rate, water and natural organic matter content, Environmental Pollution 143 (2006) 146-152.

[10] E. Davis, Ground Water Issue: Steam Injection for Soil and Aquifer Remediation. United States Environmental Protection Agency, Office of Solid Waste and Emergency Response, Washington, US, EPA/540/S-97/505, Washington, 1998.

[11] Environmental Protection Agency, Field applications of in situ remediation technologies: chemical oxidation, US Environmental Protection Agency, Washington, DC, 1998.

[12] M. Balba, N. Al-Awadhi, R. Al-Daher, Bioremediation of oil-contaminated soil: microbiological methods for feasibility assessment and field evaluation, Journal of microbiological methods 32 (1998) 155-164.

[13] Y. Son, J. Cha, M. Lim, M. Ashokkumar, J. Khim, Comparison of ultrasonic and conventional mechanical soil-washing processes for diesel-contaminated sand, Industrial \& Engineering Chemistry Research 50 (2011) 2400-2407.

[14] E.J. Anthony, J. Wang, Pilot plant investigations of thermal remediation of tar-contaminated soil and oilcontaminated gravel, Fuel 85 (2006) 443-450.

[15] J. Robinson, S. Kingman, C. Snape, H. Shang, R. Barranco, A. Saeid, Separation of polyaromatic hydrocarbons from contaminated soils using microwave heating, Separation and Purification Technology 69 (2009) 249-254.

[16] J. Robinson, E. Binner, A. Saeid, M. Al-Harahsheh, S. Kingman, Microwave processing of Oil Sands and contribution of clay minerals, Fuel 135 (2014) 153-161.

[17] E. Riser-Roberts, Remediation of petroleum contaminated soils: biological, physical, and chemical processes, CRC Press2010.

[18] S. Horikoshi, M. Muratani, K. Miyabe, K. Ohmura, T. Hirowatari, N. Serpone, M. Abe, Influence of humidity and of the electric and magnetic microwave radiation fields on the remediation of TCE-contaminated natural sandy soils, Journal of Oleo Science 60 (2011) 375-383. 
[19] T. Napier-Munn, Wills' mineral processing technology: An introduction to the practical aspects of ore treatment and mineral recovery, Elsevier Science \& Technology, 2005.

[20] ASTM International, D95-13e1 Standard Test Method for Water in Petroleum Products and Bituminous Materials by Distillation, West Conshohocken, PA, www.astm.org, 2013.

[21] A.D. Smith, E. Lester, K.J. Thurecht, J. El Harfi, G. Dimitrakis, S.W. Kingman, J.P. Robinson, D.J. Irvine, Dielectric properties of free-radical polymerizations: molecularly symmetrical initiators during thermal decomposition, Industrial \& Engineering Chemistry Research 49 (2010) 1703-1710.

[22] P. Kastanek, F. Kastanek, M. Hajek, Microwave-enhanced thermal desorption of polyhalogenated biphenyls from contaminated soil, Journal of Environmental Engineering 136 (2009) 295-300.

[23] D. Acierno, A.A. Barba, M. d'Amore, Microwaves in soil remediation from VOCs. 1: Heat and mass transfer aspects, AIChE journal 49 (2003) 1909-1921.

[24] S. Yuan, M. Tian, X. Lu, Microwave remediation of soil contaminated with hexachlorobenzene, Journal of hazardous materials 137 (2006) 878-885.

[25] International Electrotechnical Committee, I. CISPR11, Industrial, scientific and medical (ISM) radio-frequency equipment-electromagnetic disturbance characteristics-limits and methods of measurement. Consolidated, Consolidated Edition 4 (2003).

[26] A.A. Metaxas, R.J. Meredith, Industrial microwave heating, IET 1983.

[27] J. Robinson, S. Kingman, C. Snape, R. Barranco, H. Shang, M. Bradley, S. Bradshaw, Remediation of oilcontaminated drill cuttings using continuous microwave heating, Chemical Engineering Journal 152 (2009) 458463.

[28] J. Robinson, S. Kingman, C. Snape, S. Bradshaw, M. Bradley, H. Shang, R. Barranco, Scale-up and design of a continuous microwave treatment system for the processing of oil-contaminated drill cuttings, Chemical Engineering Research and Design 88 (2010) 146-154.

[29] G. Windgasse, L. Dauerman, Microwave treatment of hazardous wastes: removal of volatile and semivolatile organic contaminants from soil, Journal of microwave power and electromagnetic energy 27 (1992) 2332.

[30] H. Shang, C. Snape, S. Kingman, J. Robinson, Microwave treatment of oil-contaminated North Sea drill cuttings in a high power multimode cavity, Separation and purification technology 49 (2006) 84-90.

[31] S.B. Hawthorne, C.B. Grabanski, E. Martin, D.J. Miller, Comparisons of Soxhlet extraction, pressurized liquid extraction, supercritical fluid extraction and subcritical water extraction for environmental solids: recovery, selectivity and effects on sample matrix, Journal of Chromatography A 892 (2000) 421-433.

[32] UK Government, Department of Energy and Climate Change, Industrial Electricity Prices in the EIA, June 2015. Accessed $2^{\text {nd }}$ July 2015. https://www.gov.uk/government/statistical-data-sets/international-industrialenergy-prices. 